\title{
Tomografía de energía dual en el diagnóstico de litiasis vesicular
}

\author{
Dual energy tomography in the diagnosis of gallstones \\ Juan Pablo Reyes González, ${ }^{*}$ Alfredo Ramírez Gutiérrez de Velasco, ${ }^{*}$ Óscar Quiroz Castro ${ }^{\ddagger}$ \\ Citar como: Reyes GJP, Gutiérrez VAR, Quiroz CÓ. Tomografía de energía dual en el diagnóstico de \\ litiasis vesicular. Acta Med. 2021; 19 (1): 142-143. https://dx.doi.org/10.35366/98590
}

Masculino de 32 años de edad, sin antecedentes personales patológicos de importancia, acude al servicio de urgencias por presentar dolor abdominal transfictivo a nivel de epigastrio, acompañado de vómito de contenido alimenticio en dos ocasiones. Se solicitó estudio de tomografía abdominal por médico tratante, la cual se realizó con modalidad de energía dual, y definió múltiples imágenes redondeadas en vesícula biliar en relación a litiasis (Figura 1) así como aumento del volumen pancreático y estriación de la grasa adyacente compatible con pancreatitis Balthazar D (Figura 2).

\section{LITIASIS VESICULAR}

La litiasis vesicular es una patología frecuente, afecta de 10 a 15\% de los adultos en algún punto de su vida, puede observarse hasta en $10 \%$ de la población general, constituyendo una de las causas más comunes de problemas gastrointestinales. Aunque la mayoría de los pacientes con litiasis vesicular no desarrolla síntomas, ${ }^{1,2}$ un pequeño porcentaje desarrollará complicaciones tales como colecistitis, pancreatitis aguda e íleo biliar. 1,3,4

El estudio imagenológico de la litiasis vesicular tiene vital importancia en el manejo de los pacientes con abdomen agudo de los servicios de urgencias. ${ }^{3}$ La tomografía computarizada de abdomen ha sido establecida como una herramienta primordial de imagenología en el proceso diagnóstico en diversas patologías abdominales y como una herramienta con gran sensibilidad y especificidad en la valoración del abdomen agudo, ${ }^{5}$ aunque de forma inicial el ultrasonido continúa siendo el estudio de primera elección en pacientes con historia reciente de dolor de tipo biliar, con una especificidad superior a 95\% para litos mayores de $2 \mathrm{~mm} .{ }^{1,2}$ En la resonancia magnética la litiasis vesicular se observa mejor en imágenes contrastadas en T2 (Figura 3), e incluso puede ayudar a distinguir entre diferentes tipos de cálculos biliares, los de colesterol tienden a tener mayor intensidad en T1, mientras que los cálculos pigmentados al

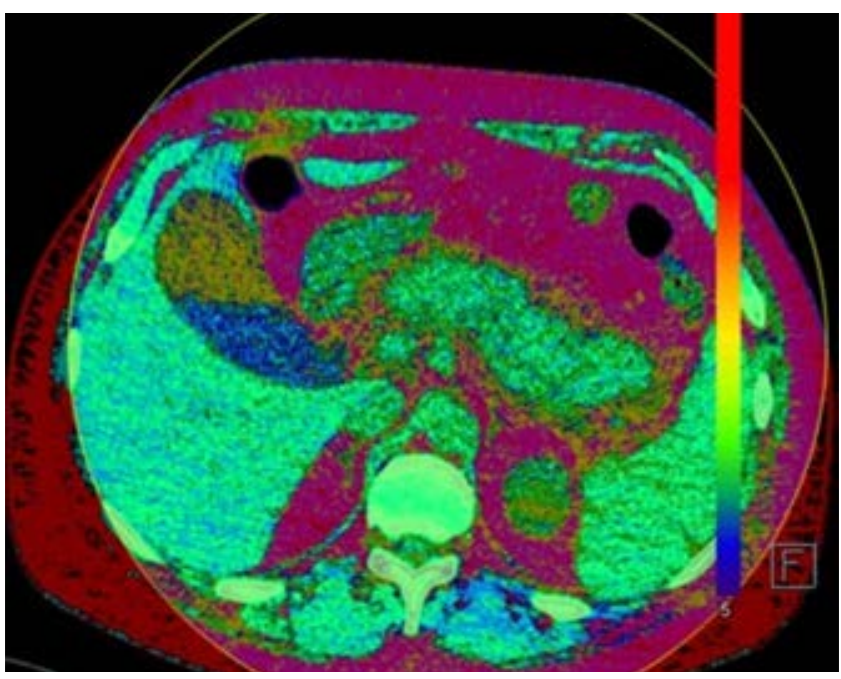

Figura 1: Corte axial de tomografía computarizada de abdomen de energía dual, donde se hacen evidentes diferentes contrastes en vesícula biliar, y se define la morfología de múltiples litos vesiculares (azul).

* Residente de Imagenología Diagnóstica y Terapéutica. Facultad de Medicina (UNAM).

‡ Jefe del Departamento de Imagenología.

Correspondencia:

Dr. Juan Pablo Reyes González

Correo electrónico: reyes.g.j.pablo@gmail.com

Aceptado: 20-04-2020.

Hospital Ángeles Pedregal, Ciudad de México. México.

www.medigraphic.com/actamedica 
igual que los de colesterol tienden a ser hipointensos en secuencias en T2, lo cual tiene implicaciones terapéuticas. ${ }^{2,6}$

La apariencia de los litos vesiculares en tomografía computarizada puede variar, los calcificados pueden distinguirse fácilmente, pero los no calcificados son isointensos en tomografías convencionales tomadas a $120 \mathrm{kVp}^{3} \mathrm{La}$ litiasis biliar isointensa y la bilis son difíciles de distinguir debido a su densidad similar; ${ }^{7}$ sin embargo, pueden diferenciarse utilizando técnicas de energía dual, distinguiendo y segmentando litos isointensos de la bilis, incluso con litos menores de $9 \mathrm{~mm} .{ }^{6}$ El principio de la tomografía de energía dual se basa en la atenuación de diversos materiales expresados en unidades Hounsfield a partir de la densidad y principalmente de su número atómico efectivo cuando son expuestos a diferentes niveles de energía del haz de rayos $X$, uno de alta energía que va de 140 a $150 \mathrm{kVp}, \mathrm{y}$ uno de baja energía que va de 80 a $100 \mathrm{kVp} .3,5,7$

Aunque la colecistectomía es el tratamiento estándar en pacientes con litiasis biliar sintomática, en casos de litiasis no calcificada puede aceptarse el uso de ácido ursodesoxi-

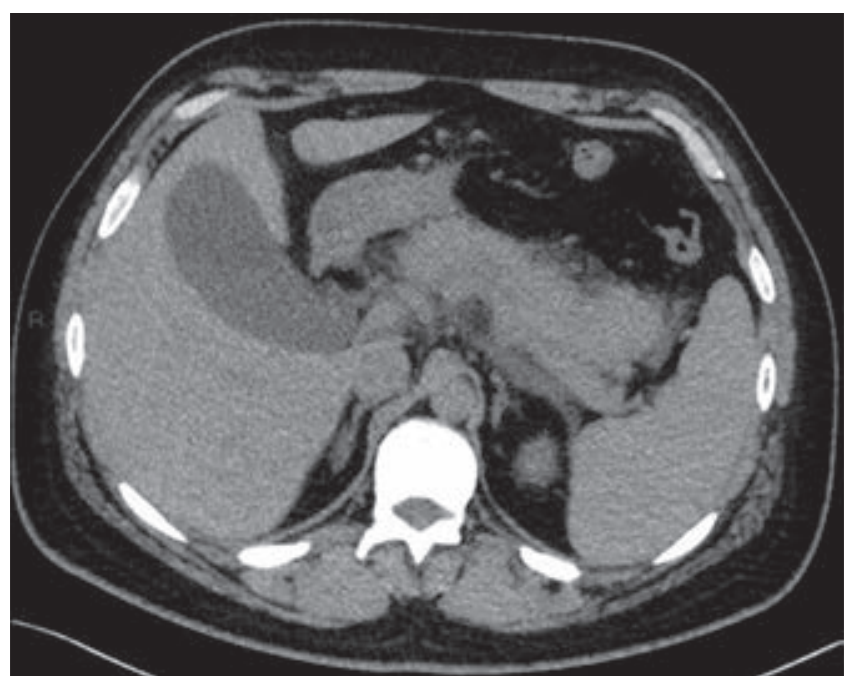

Figura 2: Corte axial de tomografía simple computarizada de abdomen donde se observa contenido de diferentes densidades en vesícula que sugiere la presencia de lodo. Nótese además el páncreas aumentado de volumen en todos sus segmentos con estriación de la grasa adyacente y líquido.

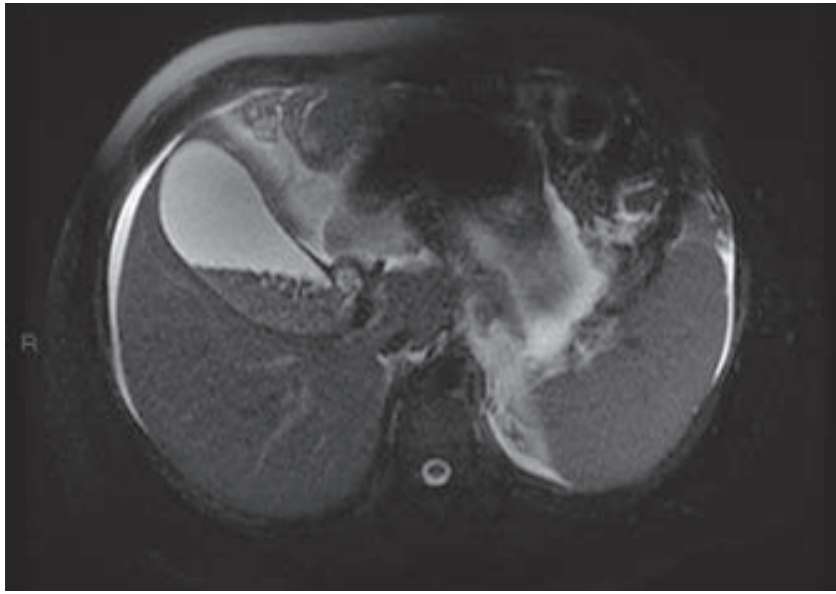

Figura 3: Corte axial de resonancia magnética en T2 con supresión grasa que revela piedras que aparecen como material hipointenso dentro de la bilis hiperintensa.

cólico ${ }^{1}$ si los litos son menores de $5 \mathrm{~mm}$, en conjunto con una vesícula funcional y un conducto cístico permeable. ${ }^{4}$

\section{REFERENCIAS}

1. Matos C. Will Dual-Energy CT Become the reference standard to evaluate gallstone disease? Radiology. 2019; 292 (2): 407-408. doi: 10.1148/radiol.2019191172.

2. Murray N, Darras K, Walstra F, Mohammed M, McLaughlin P, Nicolaou S. Dual-Energy CT in evaluation of the acute abdomen. Radiographics. 2019; 39 (1): 264-286. doi: 10.1148/rg.2019180087.

3. Chen AL, Liu AL, Wang S, Liu JH, Ju Y, Sun MY et al. Detection of gallbladder stones by Dual-Energy spectral computed tomography imaging. World J Gastroenterol. 2015; 21 (34): 9993-9998. https:// doi.org/10.3748/wjg.v21.i34.9993.

4. Catalano O, Sahani D, Kalva S, Cushing M, Hahn P, Brown J et al. MR imaging of the Gallbladder: a pictorial essay. Radiographics. 2008; 28 (1): 135-155. doi: 10.1148/rg.281065183.

5. Ratanaprasatporn L, Uyeda JW, Wortman JR, Richardson I, Sodickson AD. Multimodality imaging, including dual-energy ct, in the evaluation of gallbladder disease. Radiographics. 2018; 38 (1): 75-89. doi: 10.1148/rg.2018170076.

6. Soesbe T, Lewis M, Xi Y, Browning T, Ananthakrishnan L, Fielding J et al. A technique to identify isoattenuating gallstones with dual-layer spectral CT: an ex vivo phantom study. Radiology. 2019; 292 (2): 400-406. doi: 10.1148/radiol.2019190083.

7. Portincasa P, Di Ciaula A, de Bari O, Garruti G, Palmieri V, Wang $\mathrm{DH}$. Management of gallstones and its related complications. Expert Rev Gastroenterol Hepatol. 2015; 10 (1): 93-112. doi: 10.1586/17474124.2016.1109445. 